Elmoazzen does not anticipate any problem in reaching the goal of collecting 18000 units over the next six years, she says.

"Public cord blood banking is quite an easy sell since the umbilical cord and placenta are usually discarded," she says. "They don't really have to do anything."

In a pilot program to test and build the system, women delivering at The
Ottawa Hospital donated 950 units even though they knew those units would not be stored, says Mitchell. "So I think there's a lot of interest from women and families in the community to contribute to the public cord bank," she says.

Previously, there were two provincial public cord blood banks in Canada Héma Quebec and the Alberta Cord Blood Bank. There are also smaller public cord blood banks, such as the Victoria Angel Cord Blood Bank at the Markham-Stouffville Hospital in Markham, Ontario. In addition, private cord blood banks allow families to bank their own child's blood after paying an initial collection fee plus an annual storage charge. — Laura Eggertson, CMAJ

\title{
A home for interprofessional medical education at Dalhousie
}

$\mathrm{D}$ alhousie University in Halifax, Nova Scotia, is constructing a building where students from different health disciplines will learn together both inside and outside of the classroom to better prepare them for working as part of health care teams.

"Traditionally, the education of students in these programs has been siloed," says William Webster, dean of the university's Faculty of Health Professions. "This is a real problem. In evolving health care delivery, there is an emphasis on team delivery."

The five-storey, \$35-million building is in keeping with a shift in the curricula at the university's Centre for Collaborative Health Education, which has been evolving to better prepare students for team-based professional environments.

Currently, students in health disciplines learn in buildings scattered across campus or in leased space throughout Halifax, making some types of interprofessional education difficult.

The new building will allow faculty to teach future health professionals, including students of medicine, nursing, physiotherapy and social work, in the same location. The students will still learn most things separately, but when curriculum overlaps educators can arrange lectures, interprofessional projects or case studies to help students learn about other professions' perspectives and approaches.

The building will also house a simulation lab, where students from different disciplines can practise using each other's skillsets and competencies to provide patients with the best possible care.

Shares social spaces in the building will also encourage social mingling outside of schoolwork, says Webster.

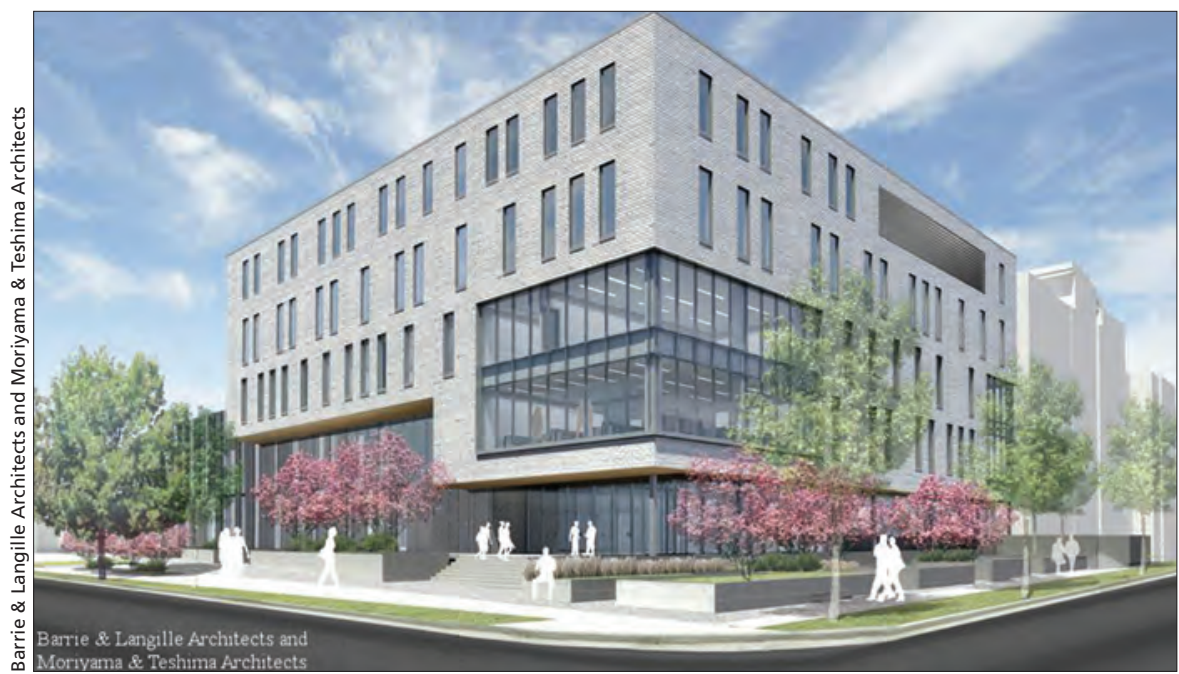

Artist's rendering of Dalhousie University's planned Collaborative Health Education Building.

"It's really about helping students understand very early on what each profession does," he says. "We're trying to instill the concept of patient and family-centred care."

Dalhousie already has a health mentors program, established in 2010, that places students in interprofessional groups of four. Each group spends time with a volunteer mentor who has a chronic health condition. The students learn how these conditions affect their mentors' daily lives as well as what it's like to navigate the health care system.

As students do this, they work on patient-centred care approaches, effective interviewing and active listening.

They also gain a better understanding of their team members' roles.

Dalhousie's curriculum is becoming increasingly interprofessional, says Alison McIntyre, a former occupational therapist who is now a second-year medical student. She represents the Dal- housie Medical Student Society at curriculum meetings and sees the building as an important step in this transition.

"It's great," she says. "Collaborative teams are the way of the future."

Students from different disciplines currently work together on group projects when their respective curricula overlap. For example, students studying occupational therapy work with social work students to make a poster that addresses an issue in their community.

The Nova Scotia government has pledged $\$ 10$ million over the next 15 years to support the building's construction and operating costs. The building will welcome its first students in September 2015.

"Interprofessional education really fits in with the government's policy on how they want health care delivery to operate," says Webster. - Catherine Cross, CMAJ

CMAJ 2013. DOI:10.1503/cmaj.109-4632 